\title{
Influence of Series Resistance on Dry-Band Discharge Characteristics on Wet Polluted Insulators
}

\author{
Takahiko Yamashita, Ryo Ishimoto and Tomohiro Furusato \\ Nagasaki University \\ Graduate School of Engineering \\ Nagasaki 852-8521, Japan
}

\begin{abstract}
This paper describes the current dependence of dry-band discharge. Model electrodes that simulated the dry-band was introduced. The dependence was examined on the voltage and current waveforms, emission spectra and their intensities, rotational temperature, etc. As a result, two different discharge types, continuous and intermittent discharges, were observed in a half cycle of applied ac voltage. They were characterized by continuous current and light emission, and by pulsative current and intermittent light emission, respectively. The duration of the continuous discharge decreased with the value of series resistance, while that of the intermittent discharge increased. The rotational temperatures of the continuous discharge and the intermittent discharge were about $6000 \mathrm{~K}$ and $1500 \mathrm{~K}$, respectively. The spectral emission intensity related to the electrolyte during the continuous discharge was higher compared with the intermittent discharge, and decreased with the value of series resistance. The spectral emission intensity related to nitrogen molecule during the intermittent discharge was almost constant irrespective of the value of series resistance. The characteristics of the continuous and intermittent discharges corresponded to those of the terminated partial arc and spark (scintillation), respectively.
\end{abstract}

Index Terms - Dry-band discharge, spectral emission, rotational temperature.

\section{INTRODUCTION}

SURFACE discharge on wet polluted insulators has been one of the serious problems because of its extremely low flashover voltage. Recently, it has attracted attention from the point of view of deterioration of polymer insulators caused by interaction between discharge and the polymeric material.

It is said that the surface discharge on wet polluted insulators takes place when the leakage current forms the dryband due to the Joule heating. When the dry-band is formed, full voltage is applied to the dry-band, and discharge takes place at the dry-band. If the residual resistance, that is the resistance of the wet polluted part, is small and the capacity of the voltage source is large, local discharge which starts from the dry-band discharge propagates on the wet polluted surface and the surface flashover takes place.

There are some mathematical models proposed to evaluate the motion of local discharge on wet polluted insulators. The models are reviewed by Rizk [1]. However, the propagation mechanism of local discharge and the discharge sustaining mechanism including dry-band discharge are not well known. The surface discharge on wet polluted insulators has inherent characteristics different from those of the static arc. The electrode fall voltage is usually several hundred volts [2]-[3],

Manuscript received on 4 September 2017, in final form 16 October 2017, accepted 16 October 2017. Corresponding author: T. Yamashita. which is much higher than that of static arc.

In addition, the interaction between the surface discharge and the insulator material has become important according to an increase in the use of polymer insulators. In order to discuss the interaction such as deterioration, the characteristics of the surface discharge should be expressed precisely. Yoshimura et al [4] reported a spectroscopic study of discharges on organic insulation, however, they used metal electrodes. Thus, research on the dry-band discharge characteristics is quite few.

On the other hand, plasma-liquid interactions have attracted attention in the field of electrochemistry. Related to water treatment etc., discharges on water have been also well investigated. They are reviewed by Bruggeman et al [5]. Mezei and Cserfalvi [6] also reviewed on electrolyte cathode atmospheric glow discharge related to the measurement of water containing toxic heavy metals.

As for the dry-band discharge, the discharge phase has not been well understood. Then the authors have investigated on its discharge mechanism. This paper describes the current dependence of the discharge which appears at the dry-band. A model electrodes that held the solution and simulated the dryband was introduced. The dependence was examined on the voltage and current waveforms, emission spectra and their intensities, rotational temperature, etc. In addition, the current dependence of discharge type was discussed. 


\section{EXPERIMENTAL SETUP AND PROCEDURE}

Figure 1 shows the arrangement of electrode system which simulated a dry-band on an insulator surface. The electrode was made of silica filter and was wetted with an aqueous solution of potassium chloride. In order to distinguish between the spectra related to electrolyte and silica filter (see Section 3.1 ), potassium chloride was used. The electrode was $20 \mathrm{~mm}$ wide and $55 \mathrm{~mm}$ long. The edge of one end was cut so that the tip of the electrode has a right angle. The other end of electrode was immersed in the aqueous solution to keep wet condition. The aqueous solution was stored in trenches made at both ends of the Bakelite box. The resistivity of the aqueous solution was measured with a conductivity meter (DKK Corporation, AOL-40) and was set to $20 \Omega \mathrm{cm}$ at 20 degree Celsius. The resistivity was set by taking the correspondence with our previous study [3] and/or various tracking and erosion tests into consideration. Two electrodes were set on a ceramic plate so that the tips of the electrodes were facing each other and had a gap of $10 \mathrm{~mm}$. When the gap length is smaller than $10 \mathrm{~mm}$, injection of the aqueous solution from silica filter into the gap sometimes disturbs the experiments. The electrodes were held with brass screws, which were also used as terminals to connect cables. The electrodes were connected to an ac high voltage source (Tokyo Transformer Co. Ltd., T-G-50). The frequency and the capacity of the transformer were $60 \mathrm{~Hz}$ and $5 \mathrm{kVA}$, respectively.

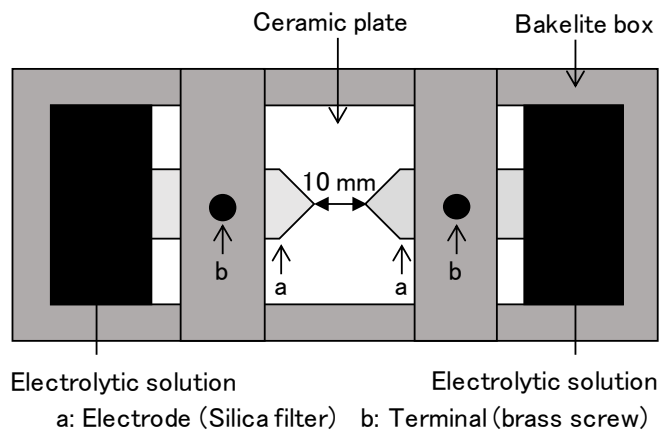

Figure 1. Electrode arrangement (top view).

Figure 2 shows a schematic diagram of the experimental setup and the measuring system. A resistor $\left(R_{1}\right)$ used to control the discharge current was connected to the electrode system in series. The resistance was varied in the range between 2 and $7 \mathrm{M} \Omega$. Ac high voltage, about $22 \mathrm{kV}$ (peak), was applied to the electrodes to initiate a dry-band discharge. The applied voltage and the values of series resistance are selected so that stable dry-band discharge can be observed. The applied voltage also should be larger than the discharge onset voltage of the gap.

The voltage along the terminals and the current measuring resistor $\left(\mathrm{R}_{2}\right)$ was measured with a high voltage probe (Iwatsu $\mathrm{H})$ and a digital oscilloscope (Tektronix Inc., DPO-4104B-L). The current was obtained from the voltage drop of a current measuring resistor $\mathrm{R}_{2}(47 \Omega)$ and the waveform was observed with the digital oscilloscope.

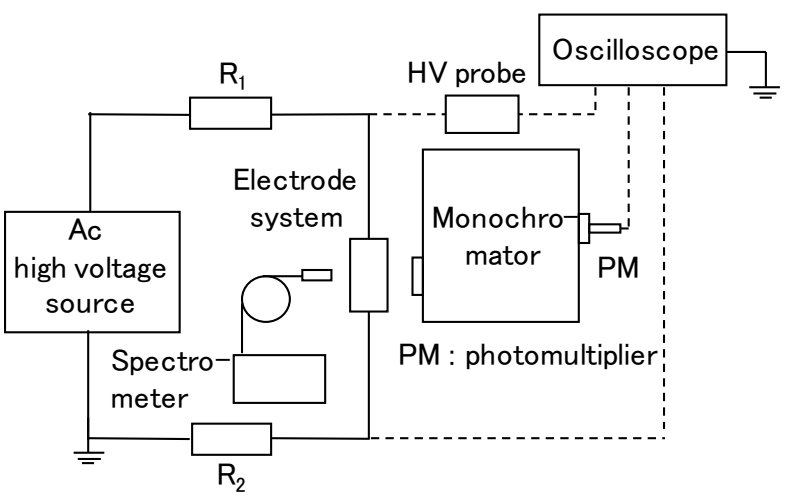

Figure 2. Schematic diagram of the experimental setup and measuring system.

The spectrum distribution from the discharge was measured with a spectrometer (BWTEK Inc., Glacier X). The temporal variations of the emission spectra related to nitrogen molecule $\left(\mathrm{N}_{2}\right.$ second positive system band: $\left.366.6 \mathrm{~nm}\right)$ and the electrolyte (K: $776.8 \mathrm{~nm})$ were measured with a monochromator (Ritsu Oyo Kougaku Co. Ltd., MC-25NP) and the digital oscilloscope. The monochromator had a 1200 lines $/ \mathrm{mm}$ diffraction grating, and the resolution was $0.2 \mathrm{~nm}$. The apertures of the input and output slits were set to $5 \mathrm{~mm}$. The distance between the discharge and the input slit was set to $200 \mathrm{~mm}$. The output light from the monochromator was converted to the electric signal with a photomultiplier (PM) system (Hamamatsu Photonics, H10720-01) and was measured with the digital oscilloscope. The discharge was also observed by taking a photograph with a digital camera (Nikon, D610). The rotational temperature was obtained by the following method.

The rotational temperature was decided from the spectral profile of the $\mathrm{N}_{2}$ second positive system band $\left(\mathrm{N}_{2} 2 \mathrm{~PB}\right)$. Apparatus function was taken into account in the calculation of the theoretical profile of $\mathrm{N}_{2} 2 \mathrm{~PB}$. It was proposed by Philips [7]. The function is expressed as follows.

a. left side from the center:

$$
g_{1}(\Delta \lambda)=\frac{\mathrm{a}_{1}-\left(\Delta \lambda / \mathrm{w}_{1}\right)^{2}}{\mathrm{a}_{1}+\left(\mathrm{a}_{1}-2\right)\left(\Delta \lambda / \mathrm{w}_{1}\right)}
$$

where, $\Delta \lambda$ is the difference of the wave length from the center $\lambda_{0}, \mathrm{~W}_{1}$ is a half value of full-width at half-maximum (FWHM) of the left side from the center, as shown in Figure 3, and $\mathrm{a}_{1}=$ $\left(\mathrm{S}_{1} / \mathrm{W}_{1}\right)^{2} \cdot S_{1}$ is a value shown in Figure 3.

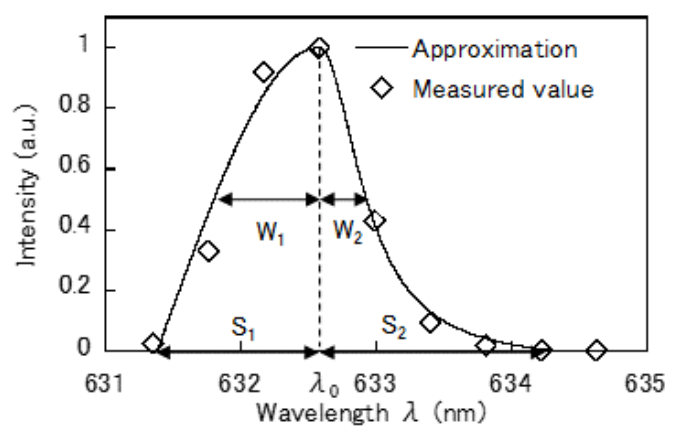

Figure 3. Apparatus function of the spectrometer used in this study. 
b. right side from the center:

$$
g_{2}(\Delta \lambda)=\frac{\mathrm{a}_{2}-\left(\Delta \lambda / \mathrm{w}_{2}\right)^{2}}{\mathrm{a}_{2}+\left(\mathrm{a}_{2}-2\right)\left(\Delta \lambda / \mathrm{w}_{2}\right)}
$$

where, $\mathrm{W}_{2}$ is a half value of FWHM of the right side, and $\mathrm{a}_{2}=\left(\mathrm{S}_{2} / \mathrm{W}_{2}\right)^{2} \cdot \mathrm{S}_{2}$ is a value shown in Figure 3.

The apparatus function was obtained with helium-neon (He$\mathrm{Ne}$ ) laser (Uniphase, 1507-0). The example of the measured profile of the apparatus function of the spectrometer used in this study is shown in Figure 3. The profile of emission spectra of $\mathrm{N}_{2}$ second positive system band $\left(\mathrm{N}_{2} 2 \mathrm{~PB}\right)$ varies with the rotational temperature of nitrogen molecule, as shown in Figure 4. By fitting the measured data to the calculated curve, the rotational temperature was obtained.

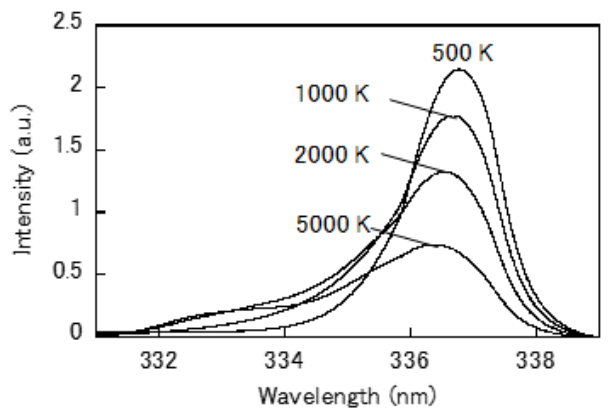

Figure 4. Theoretical profiles of spectrum intensity distribution of $\mathrm{N}_{2} 2 \mathrm{~PB}$ as a parameter of rotational temperature.

\section{EXPERIMENTAL RESULTS}

\subsection{TYPICAL DISCHARGE PATTERNS}

Figures 5 and 6 show examples of the results of simultaneous measurement of voltage and current waveforms, and light emission of dry-band discharge. Two types of dryband discharges were observed. One is characterized by pulsative current and intermittent light emission, as shown in Figure 5. The authors named the discharge of this type "intermittent discharge". The voltage in the period of current pulse was supposed to be insufficient to sustain a continuous dry-band discharge. The other one is characterized by continuous current and light emission, as shown in Figure 6. The authors named the discharge of this type "continuous discharge". The intermittent discharge was observed at relatively high value of series resistance. On the other hand, the continuous discharge was observed at relatively low value of series resistance.

Figures 7 and 8 show the distributions of the emission spectra measured with the spectroscope. They show the cases in which the series resistances were 2 and $7 \mathrm{M} \Omega$, respectively. The intensity of the spectrum related to the electrolyte was found to be quite strong (about 80) when $R_{1}=2(\mathrm{M} \Omega$ ). On the other hand, the spectrum intensity of $\mathrm{N}_{2} 2 \mathrm{~PB}$ was found to be comparable irrespective of the value of the series resistance, as shown in Figures 7 and 8 . The spectrum intensity related to the electrolyte was quite small when $R_{1}=7(\mathrm{M} \Omega)$, as shown in Figure 8. However, the appearance of the spectrum related to the electrolyte is very important to discuss the sustaining

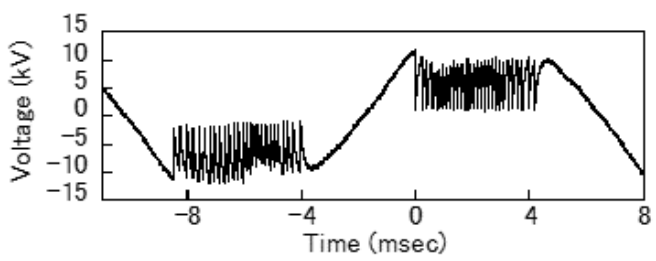

(a) Voltage waveform

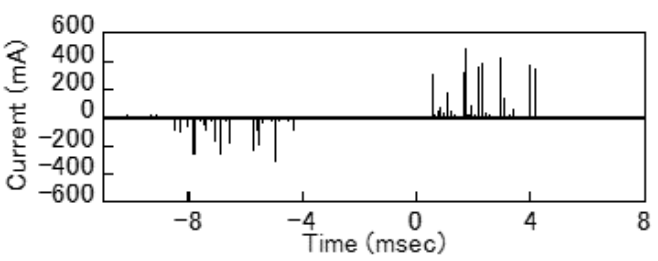

(b) Current waveform

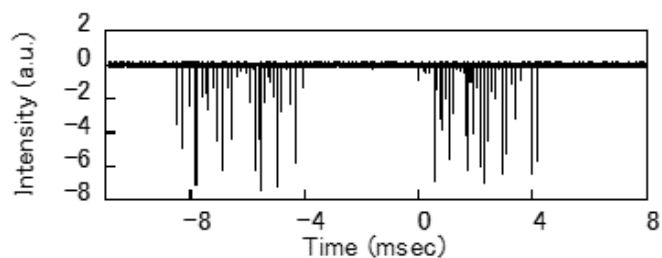

(c) Temporal variation of light emission

Figure 5. An example of the results of simultaneous measurement of voltage and current waveforms, and temporal variation of light emission $\left(R_{1}=7(\mathrm{M} \Omega)\right)$.

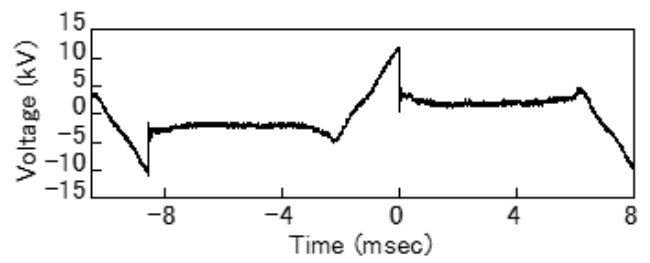

(a) Voltage waveform

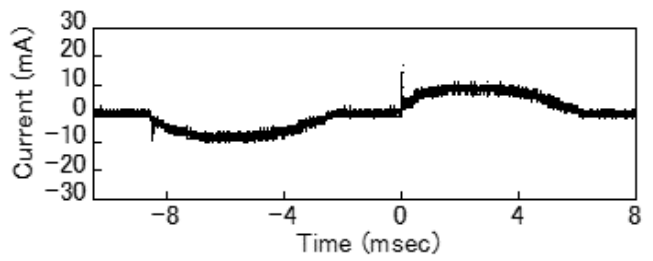

(b) Current waveform

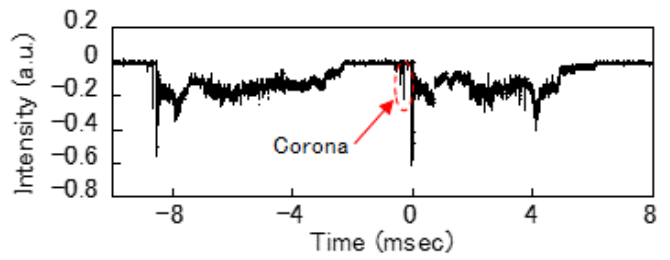

(c) Temporal variation of light emission

Figure 6. An example of the results of simultaneous measurement of voltage and current waveforms, and temporal variation of light emission $\left(R_{1}=2\right.$ $(\mathrm{M} \Omega))$.

mechanism of the intermittent discharge. By the way, the spectrum around $589 \mathrm{~nm}$ in Figure 7 corresponded to the light emission of sodium $(\mathrm{Na})$ that was supposed to come from the silica filter owing to the high temperature caused by the dryband discharge (see Figure 9). 


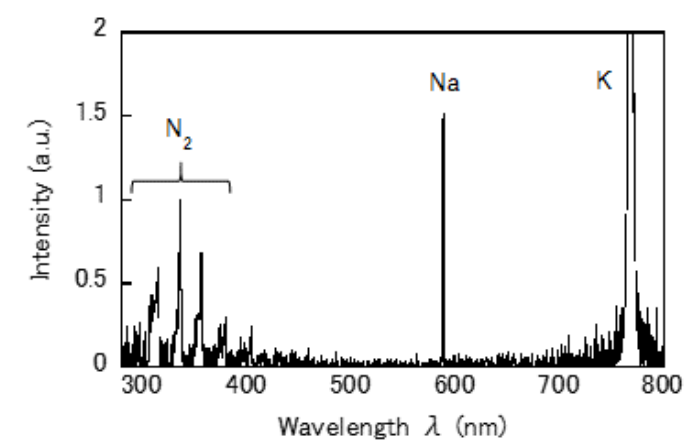

Figure 7. An example of the distribution of emission spectra from dry-band discharge $\left(R_{1}=2(\mathrm{M} \Omega)\right)$.

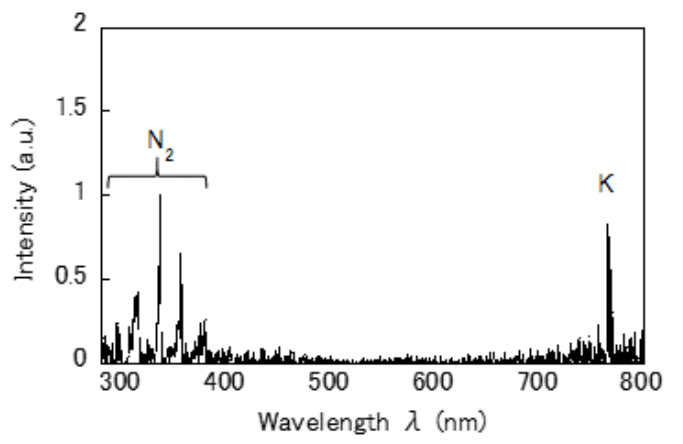

Figure 8. An example of the distribution of emission spectra from dry-band discharge $\left(R_{1}=7(\mathrm{M} \Omega)\right)$.

Figure 9 shows the theoretical and measured profiles of the emission spectra of $\mathrm{N}_{2} 2 \mathrm{~PB}$. From the fitting results, the

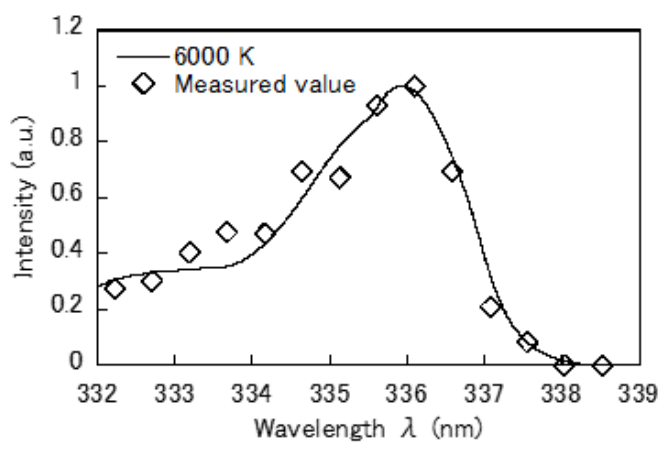

(a) $R_{1}=2(\mathrm{M} \Omega)$

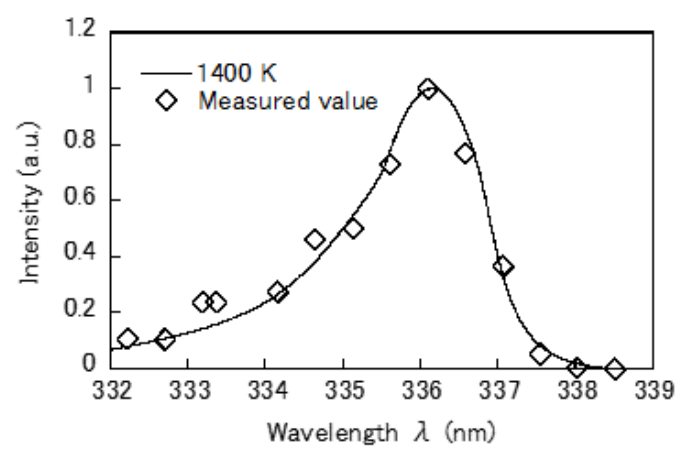

(b) $R_{1}=7(\mathrm{M} \Omega)$ rotational temperature was about $6000 \mathrm{~K}$ when $R_{1}=2(\mathrm{M} \Omega)$. On the other hand, it was about $1500 \mathrm{~K}$ when $R_{1}=7(\mathrm{M} \Omega)$. The rotational temperature of continuous discharge was quite higher than that of the intermittent discharge. Thus, these two types of discharges have different characteristic. The modal shift of dry-band discharge seems to appear according to the value of the series resistance. The difference in the rotational temperature is also very important to discuss the sustaining mechanism of the dry-band discharge.

\subsection{VARIATION OF WAVEFORMS WITH SERIES RESISTANCE}

Under the condition where the series resistance had the middle value between 2 and $7 \mathrm{M} \Omega$, the mixture of two types of dry-band discharges were observed. The typical waveforms when $R_{1}=5(\mathrm{M} \Omega)$ are shown in Figure 10. Two types of the discharge alternately appeared in a half cycle of the applied voltage.

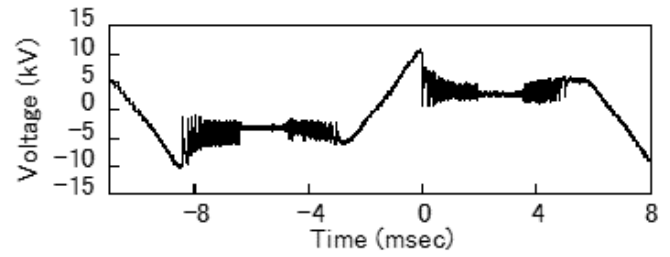

(a) Voltage waveform

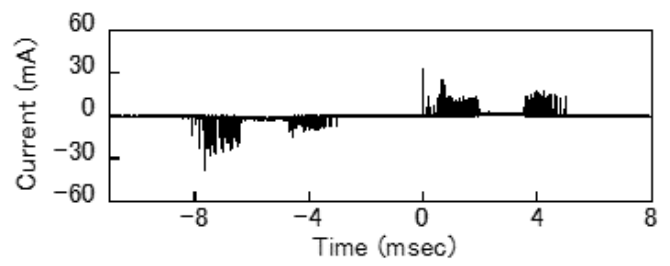

(b) Current waveform

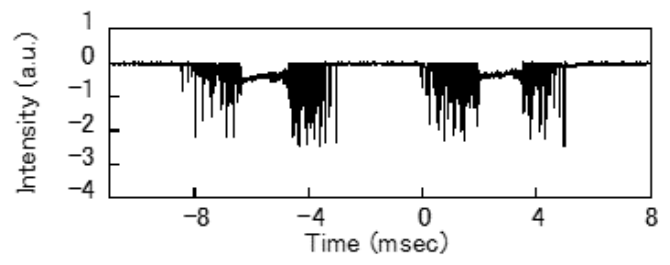

(c) Temporal variation of light emission

Figure 10. An example of the results of simultaneous measurement of voltage and current waveforms, and temporal variation of light emission $\left(R_{1}=5(\mathrm{M} \Omega)\right)$.

From Figures 5, 6 and 10, the duration of each discharge type was revealed to vary with the value of series resistance. The duration of each discharge type was measured from the voltage and current waveforms and the temporal variation of light emission. Figure 11 shows the variation of the ratio of the duration of each discharge type as a function of the value of series resistance. The ratio was obtained from the duration of each discharge type divided by the total discharge period. The ratio of continuous discharge decreased with the value of series resistance. On the other hand, the ratio of intermittent discharge increased with the value of series resistance.

Figure 9. Estimation of rotational temperatures $\left(R_{1}=2\right.$ and $\left.7(\mathrm{M} \Omega)\right)$. 


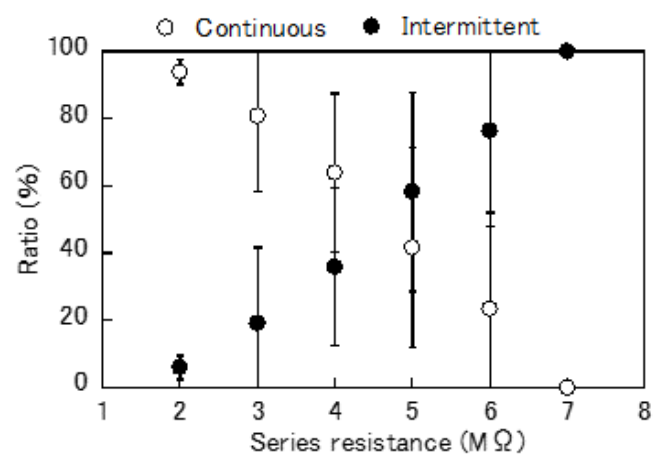

Figure 11. Variation of the ratios of the durations of the continuous and intermittent discharges as a function of the value of series resistance.

\subsection{VARIATION OF SPECTRAL EMISSION WITH SERIES RESISTANCE}

Figure 12 shows examples of the temporal variation of the spectral emission of $\mathrm{N}_{2}$ 2PB $(366.6 \mathrm{~nm})$. Peak value of the spectral emission of $\mathrm{N}_{2} 2 \mathrm{~PB}$ appeared during the intermittent discharge.

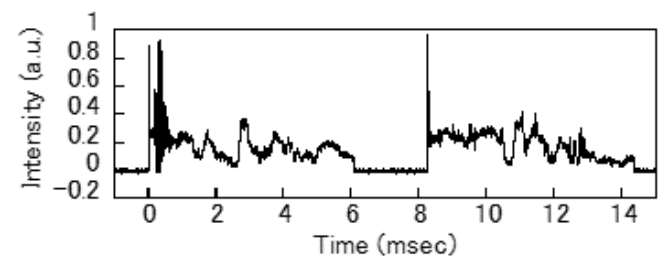

(a) $R_{1}=2(\mathrm{M} \Omega)$

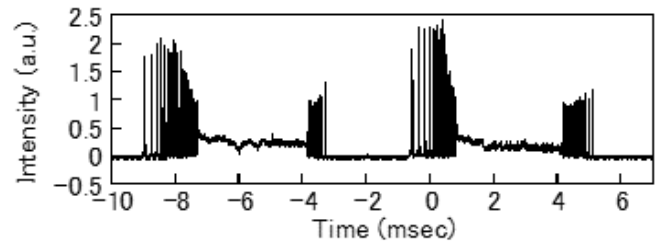

(b) $R_{1}=4(\mathrm{M} \Omega)$

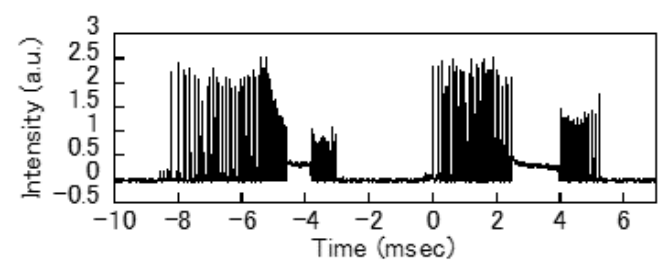

(c) $R_{1}=6(\mathrm{M} \Omega)$

Figure 12. Examples of the temporal variation of the spectral emission related to $\mathrm{N}_{2}(366.6 \mathrm{~nm})$.

Figure 13 shows the examples of the temporal variation of the spectral emission related to the electrolyte $(\mathrm{K}: 776.8 \mathrm{~nm})$. The peak value appeared during the continuous discharge when $R_{1}=2(\mathrm{M} \Omega)$, as shown in Figure 13a. The peak value of the spectral emission during the continuous discharge decreased with the value of series resistance. When the series resistance was higher than $4 \mathrm{M} \Omega$, the peak value of the spectral emission during the continuous discharge was comparable compared with that of the intermittent discharge.

Figure 14 shows the relation between the peak value of the spectral emission related to nitrogen molecule and the series

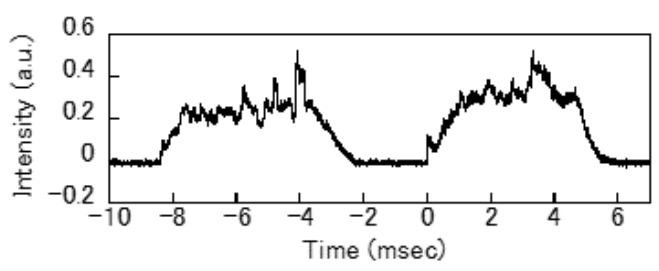

(a) $R_{1}=2(\mathrm{M} \Omega)$

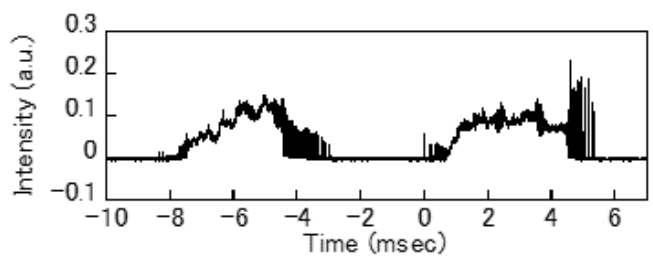

(b) $R_{1}=4(\mathrm{M} \Omega)$

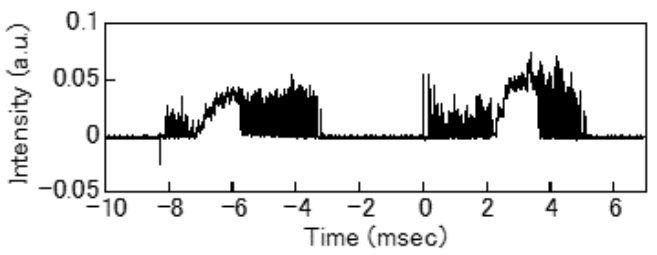

(c) $R_{1}=6(\mathrm{M} \Omega)$

Figure 13. Examples of the temporal variation of the spectral emission related to $\mathrm{K}(776.8 \mathrm{~nm})$.

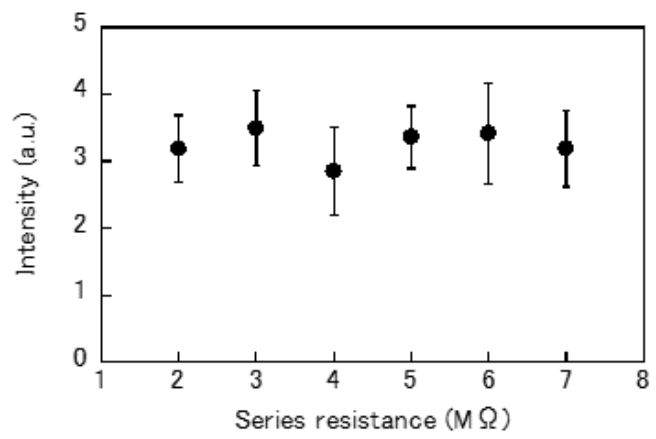

Figure 14. Relation between the spectral emission intensity related to nitrogen molecule $(366.6 \mathrm{~nm})$ and the value of series resistance.

resistance. The peak value appeared during the intermittent discharge in a half cycle. The peak value of the spectral emission intensity of $\mathrm{N}_{2} 2 \mathrm{~PB}$ was almost constant irrespective of the value of series resistance. In Figures 7 and 8 , the spectrum intensity of $\mathrm{N}_{2} 2 \mathrm{~PB}$ was found to be comparable irrespective of the value of the series resistance. The result was supported by the result in Figure 14.

Figure 15 shows the relation between the spectral emission related to the electrolyte $(\mathrm{K}: 776.8 \mathrm{~nm})$ and the series resistance. The peak value of the spectral emission of $\mathrm{K}$ decreased with the value of series resistance in the range from 2 to $4 \mathrm{M} \Omega$. The peak value was almost constant when the series resistance was higher than $4 \mathrm{M} \Omega$. In Figures 7 and 8, the intensity of the spectrum of $\mathrm{K}$ was quite strong when $R_{1}=2$ (M $\Omega)$. On the other hand, it was small when $R_{1}=7$ (M $\left.\Omega\right)$. The result was also supported by the result in Figure 15 .

Figure 16 shows the relation between the peak value of the current during the continuous discharge and the value of series 


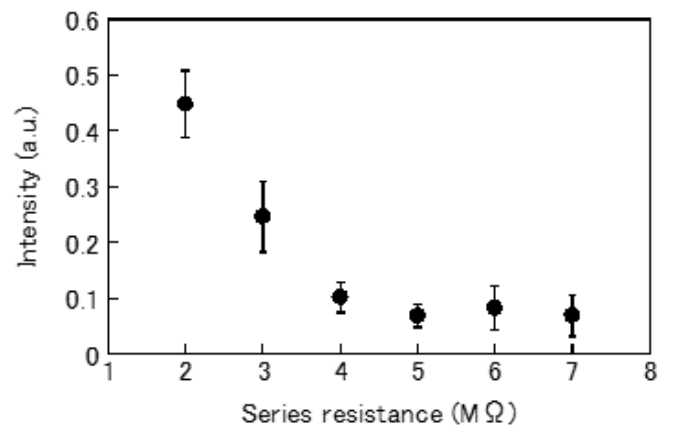

Figure 15. Relation between the spectral emission intensity related to the electrolyte $(\mathrm{K}: 776.8 \mathrm{~nm})$ and the value of series resistance.

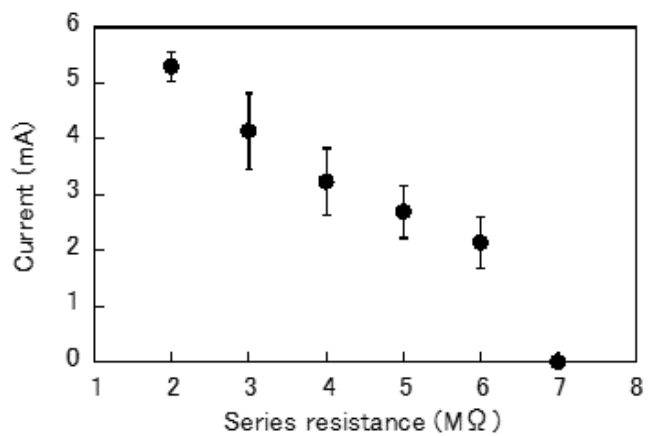

Figure 16. Relation between the peak value of the current during continuous discharge and the value of series resistance.

resistance. The peak value of the current during the continuous discharge was almost in inverse proportion to the value of series resistance, except for the case of $7 \mathrm{M} \Omega$. When $R_{1}=7$ $(\mathrm{M} \Omega)$, almost no continuous discharge was observed.

Figure 17 shows the relation between the peak value of the spectral emission related to $\mathrm{K}$ and the peak value of the current during the continuous discharge. In the case of the continuous discharge, the peak value of the spectral emission intensity increased with the peak of the current. The spectral emission related to the electrolyte was found to be strongly affected by the current when the peak value of the continuous current was larger than $3 \mathrm{~mA}$.

The peak value of the spectral emission which was related to the electrolyte during the continuous discharge decreased with the value of series resistance. On the other hand, the spectral emission intensity of $\mathrm{N}_{2} 2 \mathrm{~PB}$ was almost constant

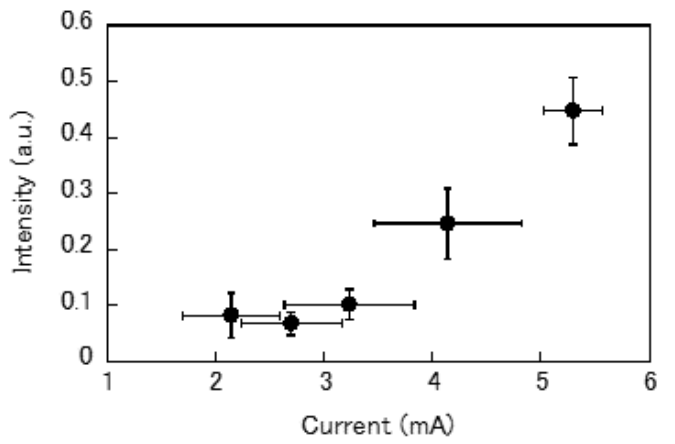

Figure 17. Relation between the peak value of the spectral emission intensity of $\mathrm{K}$ and the peak value of the current during the period of continuous discharge. irrespective of the value of series resistance and the discharge type. However, it is important that the spectral emission related to the electrolyte was observed even in the case of the intermittent discharge. Details will be discussed in the DISCUSSION.

\section{DISCUSSION}

\subsection{VOLTAGE AND CURRENT WAVEFORMS}

When the value of the current limiting resistance is small, the voltage along the discharge is supposed to be high enough to sustain the discharge. Then, the dry-band discharge becomes continuous and the current becomes a conduction current. On the other hand, the voltage along the discharge is supposed to be insufficient to sustain the discharge when the value of the current limiting resistance is large. Then, the discharge disappears immediately.

In order to discuss individual current pulse, we introduced an equivalent circuit as shown in Figure 18. The series resistor, which is a solid resistor, has capacitive component which is dominant at high frequency. Figure 19 shows individual current pulse and corresponding voltage between the terminals.

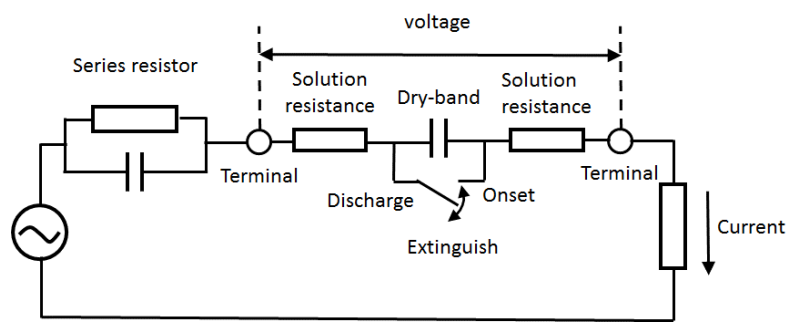

Figure 18. Equivalent circuit.

Before onset of the discharge, the voltage is almost the same as the voltage between the electrodes and as the output voltage of the transformer. When the voltage reaches the discharge onset voltage (a in Figure 19), discharge appears at the gap and the voltage rapidly decreases. At the same time, the voltage along the series resistor rapidly increases and pulse current flows through the circuit. If the residual voltage between the terminals ( $b$ in Figure 19) is not high enough to sustain the discharge, discharge extinguishes immediately. As shown in Figure 18, the electrodes also forms a capacitance.

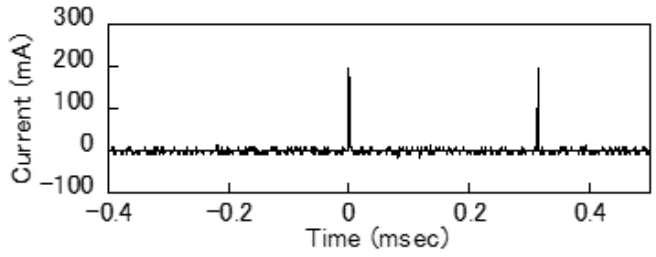

(a) Current

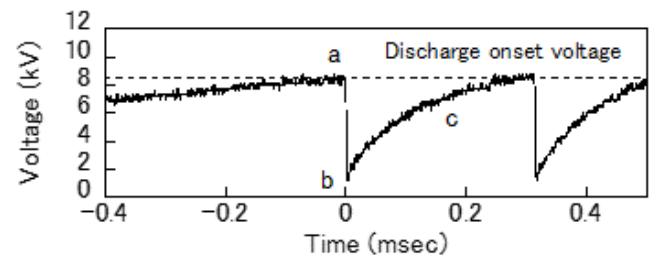

(b) Voltage

Figure 19. Individual current pulse and corresponding voltage. 
After the discharge disappears, the capacitance is charged again. As a result, the voltage between the terminals increases (c in Figure 19) and the voltage along the series resistor decreases. Thus, it is concluded that the current is an apparent current and its peak value does not have an important meaning.

\subsection{CHARACTERISTICS OF CONTINUOUS AND INTERMITTENT DISCHARGES}

At the value of the series resistance of $2 \mathrm{M} \Omega$, the continuous discharge was mainly observed. On the other hand, at $7 \mathrm{M} \Omega$ the intermittent discharge was only observed. Then, the rotational temperature of nitrogen was measured in each case. The rotational temperature was about $1500 \mathrm{~K}$ at $7 \mathrm{M} \Omega$ of series resistance, and was about $6000 \mathrm{~K}$ at $2 \mathrm{M} \Omega$. Although these temperatures are in the range reported by Bruggeman, et al. [5], they are different from each other.

The spectral emission related to the electrolyte at $7 \mathrm{M} \Omega$ of the series resistance is quite small. On the other hand, the spectral emission at $2 \mathrm{M} \Omega$ is much higher than that of $7 \mathrm{M} \Omega$, as mentioned in the section 3.1. These results indicate that the continuous discharge is an arc-like discharge. Therefore, it is supposed that the continuous discharge corresponds to a terminated partial arc. On the other hand, the characteristics of the intermittent discharge is different from the arc phase. The intermittent discharge will correspond to a spark (or scintillation).

\subsection{DEPENDENCE OF SPECTRAL EMISSION ON SERIES RESISTANCE}

As mentioned in the section 3.3, the intensity of the spectral emission related to the electrolyte depends on the value of series resistance. The spectral emission in the case of the continuous discharge normalized by the current decreased with the value of series resistance. In order to discuss the reason, photographs of the discharges were examined.

Figure 20 shows the typical photographs of the dry-band discharges. Figures on the right hand side show the outline images of the area of orange light emission. These photographs were taken with $1 / 250$ s shutter speed. Figure $20 \mathrm{a}$ shows the example when $R_{1}=2(\mathrm{M} \Omega)$. Orange light emission related to the potassium can be seen entire the discharge channel. When the value of the series resistance increased, the area of orange light emission was reducing, as shown in Figures $20 \mathrm{~b}$ and $\mathrm{c}$. When $R_{1}=7(\mathrm{M} \Omega)$, the area was localized just around the tip of the electrodes, and only a faint light emission could be seen (pointed by an arrow) as shown in Figure 20c. This means that the spatial volume of the discharge channel which emits orange light decreases with the value of series resistance. The authors supposed that it was one of the reasons why the intensity of the spectral emission related to the electrolyte decreased with the value of series resistance.

The strong spectral emission related to the electrolyte during the continuous discharge indicates the activity of high energy particle bombardment. In the case of intermittent discharge, since the spectral emission related to the electrolyte is small, the bombardment is supposed not to be active. However, since the process is supposed to be existed, the

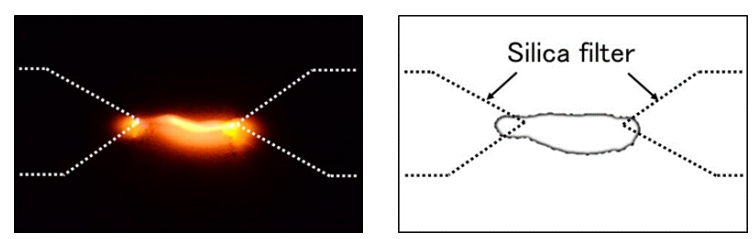

(a) $R_{1}=2(\mathrm{M} \Omega)$

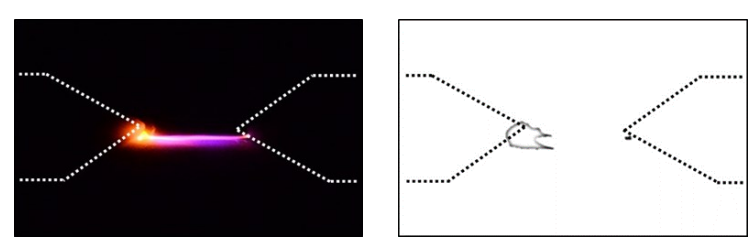

(b) $R_{1}=4(\mathrm{M} \Omega)$

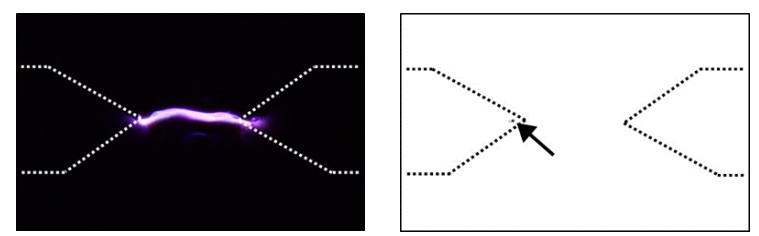

(c) $R_{1}=7(\mathrm{M} \Omega)$

Figure 20. Photographs of the dry-band discharges.

intermittent discharge may also cause the spattering of the insulator material. The bombardment of high energy particle such as nitrogen molecule ion [5] during continuous discharge leads to the deterioration of the insulator material such as erosion and/or tracking if organic material is used. The relation between the leakage current and the erosion was investigated (e. g. [8]).

During the intermittent discharge, the spectral emission related to nitrogen molecule is dominant. Since the spectral emission related to nitrogen molecule includes relatively short wavelength spectra, the energy is relatively high. This means that the intermittent discharge may affect the properties of the material surface such as hydrophobicity change. The effect of corona such as hydrophobicity change and etc. was also investigated (e. g. [9]-[10]).

\subsection{DISCHARGE PHASE AND MODAL SHIFT OF DRY-BAND DISCHARGE}

As mentioned in Section 3.2, the dominant discharge type depends on the value of series resistance. When the value of series resistance is relatively small, continuous discharge is dominant. On the other hand, the intermittent discharge is dominant when the value of series resistance is relatively large. From Figure 11, the modal shift of dry-band discharge is explained by the ratio of each discharge type. However, the ratio varies gradually with the value of series resistance. In Section 3.3, it was revealed that the spectral emission related to the electrolyte varies with the value of the series resistance and the current. From Figure 17, the intensity of the spectral emission increases with the continuous current when the current is more than a few $\mathrm{mA}$. Therefore, a few $\mathrm{mA}$ of the continuous current is supposed to be a criterion of the modal shift of the dry-band discharge under the present experimental conditions. 


\section{CONCLUSION}

In this paper, the current dependence of the dry-band discharge was examined. A model electrodes that simulates the dry-band was introduced. The dependence was examined on the voltage and current waveforms, emission spectra and their intensities, rotational temperature, etc. In addition, the discharge phase was discussed. The following results were obtained.

(1) Two different types of dry-band discharges were observed depending on the value of current limiting resistance. One is characterized by the pulsative current and intermittent light emission. The authors named the discharge of this type "intermittent discharge". The other one is characterized by the continuous current and light emission. The authors named the discharge of this type "continuous discharge".

(2) The ratio of the duration of each discharge varied with the resistance. In the case of relatively high resistance such as $7 \mathrm{M} \Omega$, intermittent discharge was dominant. On the other hand, continuous discharge was dominant in the case of relatively low resistance such as $2 \mathrm{M} \Omega$.

(3) Rotational temperature was estimated from the profile of spectral emission of molecular nitrogen second-positivesystem band. The temperature was revealed to be about $1500 \mathrm{~K}$ for the intermittent discharge, and about $6000 \mathrm{~K}$ for the continuous discharge.

(4) Spectral emission of potassium which is a component of the electrolyte was strong in the case of continuous discharge when the value of the series resistance was relatively small. In the case of intermittent discharge, the spectral emission of potassium was faintly observed. On the other hand, the intensity of spectral emission of molecular nitrogen was almost constant irrespective of the value of the current limiting resistance. The spectral emission of $\mathrm{N}_{2}$ was dominant during the intermittent discharge.

(5) Orange light emission of potassium was observed along the discharge channel. However, it became to be localized around the electrodes, and its area decreased with the value of series resistance.

(6) The modal of the dry-band discharge was revealed to vary with the current. A few $\mathrm{mA}$ of the continuous current is supposed to be a criterion of the modal shift under the present experimental conditions.

The effects of the resistivity and of the kind of the electrolyte will be examined in the future.

\section{AKNOWLEDGEMENTS}

This work was partially supported by the Japanese Ministry of Education, Culture, Sports Science and Technology (Grantin-Aid for Scientific Research (C) 16K06231).

\section{REFERENCES}

[1] F. A. M Rizk, "Mathematical models for pollution flashover", Electra, Vol.78, pp.71-103, 1981.

[2] P. Bruggeman, E. Ribežl, A. Maslani, J. Degroote, A. Malesevic, R. Rego, J. Vierendeels and C. Leys, "Characteristics of atmospheric pressure air discharges with a liquid cathode and a metal anode", Plasma Source Sci. Technol., Vol.17, 025012 (11pp), 2008.

[3] T. Yamashita, H. Matsuo, H. Fujiyama and T. Oshige, "Electrode-Fall of Local Discharge on an Electrolytic Surface", IEEE Trans. Electr. Insul., Vol.23, No. 6, pp. 979-986, 1988.

[4] N. Yoshimura, M. Nishida, and F. Noto, "Light Emission from Tracking Discharges on Organic Insulation", IEEE Trans. Electr. Insul., Vol. 19, No. 2, pp. 149-155, 1984.

[5] P. J. Bruggeman, M. J. Kurshner, B. R. Locke, J. G. E. Gardeniers, W. G. Graham, D. B. Graves, H. C. H. M. Hofman-Caris, D. Maric, J. P. Reid, E. Ceriani, D. Fernandez Rivas, J. E. Foster, S. C. Garrick, Y. Gorbanev, S. Hamaguchi, F. Iza, H. Jablonowski, E. Klimova, J. Kolb, F. Krema, P. Lukes, Z. Machala, I. Marinov, D. Mariotti, S. Mededovic Thagard, D. Minakata, E. C. Nevts, J. Pawlat, Z. Lj Petrovic, R. Pflieger, S. Reuter, D. C. Schram, S. Schröter, M. Shiraiwa, B. Tarabová, P. A. Tsai, J. R. R. Verlet, T. von Woedike, K. R. Wilson, K. Yasui and G. Zvereva, "Plasma-liquid interactions: a review and roadmap", Plasma Source Sci. Technol., Vol. 25, 053002 (59pp), 2016.

[6] P. Mezei and T. Cserfalvi, "Electrolyte Cathode Atmospheric Glow Discharges for Direct Solution Analysis", Applied Spectroscopy Reviews, Vol.42, pp.573-604, 2007.

[7] D. M. Phillips, "Determination of gas temperature from unresolved bands in the spectrum from a nitrogen discharge", J. Phys. D: Appl. Phys., Vol. 8, pp. 507-521, 1975.

[8] J. H. Kim, W. C. Song, J. H. Lee, Y. K. Park, H. G. Cho, Y. S. Yoo and K. J. Yang, "Leakage Current Monitoring and Outdoor Degradation of Silicone Rubber", IEEE Trans. Dielect. Electr. Insul., Vol. 8, pp.1108$1115,2001$.

[9] V. M. Moreno and R. S. Gorur, "Effect of Long-term Corona on Nonceramic Outdoor Insulator Hausing Material”, IEEE Trans. Dielect. Electr. Insul., Vol. 8, pp. 117-128, 2001.

[10] I. J. S. Lopes, S. H. Shesha, H. Jayaram and E. A. Cherney, "A Study of Partial Discharges from Water Droplets on a Silicone Rubber Insulating Surface", IEEE Trans. Dielect. Electr. Insul., Vol. 8, pp. 262-268, 2001.

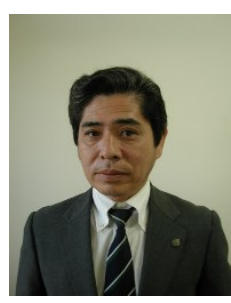

Takahiko Yamashita (M'00) was born in Fukuoka, Japan, in 1957. He received the B.E., M.E. and D.E. degrees from Kyushu University in 1980, 1982 and 1985, respectively. He has been working in Nagasaki University, Nagasaki, Japan since 1985 . $\mathrm{He}$ is a Professor of Graduate School of Engineering and a Vice President of Nagasaki University. He is a senior member of Institute of Electrical Engineers Japan. His research interests are discharge on wet-polluted surface, and other discharge phenomena.

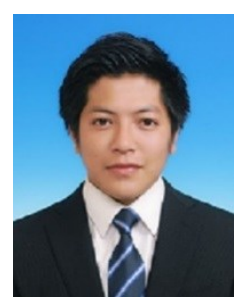

Ryo Ishimoto (non-member) was born in Yamaguchi, Japan, in 1994. He received the B.S., degree form Nagasaki University, Nagasaki Japan, in 2017. He is currently a M.S. course student of Graduate School of Engineering in Nagasaki University. $\mathrm{He}$ is mainly engaged in the elucidation of the mechanism of the dryband discharge under a contamination wet condition on insulator surface.

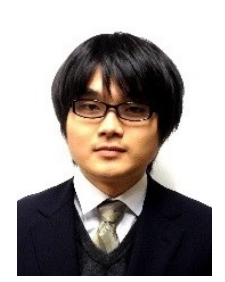

Tomohiro Furusato (M'11) was born in Kagoshima, Japan, in 1988. He received the B.S., M.S., and Ph.D. degrees from Kumamoto University, Kumamoto Japan, in 2011, 2012, and 2014, respectively. He was with the Japan Society for the Promotion of Science, Kumamoto University, from 2013 to 2014, as a Research Fellow. Since 2014, he has been an Assistant Professor with the Graduate School of Engineering, Nagasaki University, Nagasaki, Japan. His research interests are pulsedpower, creeping discharge, and discharge phenomena in supercritical fluids. 